\title{
Conjugate Cellular Automata and Neural Network Approach: Failure Load Prediction of Masonry Panels
}

\author{
Iuliia Glushakova $\mathbb{D}^{1},{ }^{1}$ Qihan Liu, ${ }^{2}$ Yu Zhang ${ }^{1},{ }^{1}$ and Guangchun Zhou ${ }^{1}$ \\ ${ }^{1}$ School of Civil Engineering, Harbin Institute of Technology, Harbin 150090, China \\ ${ }^{2}$ Department of Media Technology and Art, Harbin Institute of Technology, Harbin 150090, China \\ Correspondence should be addressed to Yu Zhang; zhangyuhit@hit.edu.cn
}

Received 12 January 2020; Revised 10 June 2020; Accepted 17 June 2020; Published 11 July 2020

Academic Editor: Filippo Ubertini

Copyright (C) 2020 Iuliia Glushakova et al. This is an open access article distributed under the Creative Commons Attribution License, which permits unrestricted use, distribution, and reproduction in any medium, provided the original work is properly cited.

\begin{abstract}
The intricate interplay between the microscopic constituents and their macroscopic properties for masonry structures complicates their failure analysis modelling. A composite strategy incorporating neural network (NN) and cellular automata (CA) is developed to predict the failure load for masonry panels with and without openings subjected to lateral loadings. The discretized panels are modelled by the CA methodology using nine neighbour cells, which derive their state values from geometric parameters and opening location placement for the panels. An identification coefficient dictated by these geometric parameters and experimental data is fed together as the input training data for the NN. The NN uses a backpropagation algorithm and two hidden layers with sigmoid activation functions to predict failure loads. This method achieves greater accuracy in prediction when compared with the yield line and finite elemental analysis (FEA) methods. The results attained elucidate the feasibility of the current methodology to complement conventional approaches such as FEA to provide additional insight into the failure mechanism of masonry panels under varied loading conditions.
\end{abstract}

\section{Introduction}

Masonry structures have a long history spanning centuries of usage due to simplicity in their construction and durability [1]. They are continuously subjected to dynamic loadings and intermittent abusive loadings such as earthquakes and floods. Generally, structural responses, e.g., displacements, velocities, and bending, are recorded and inversely solved for dynamic loads due to technological and economic constraints in direct measurement of external dynamic loads [2]. Various models have been proposed and can broadly be grouped under frequency-domain $[3,4]$ or time-domain $[5,6]$. Innovative techniques such as the application of stochastic simulation of Griffith flaws [7] or a combination of topology optimization method and phasefield design [8] have been proposed to improve the modelling of the load and resistance of building materials. More attention is now paid on finding ways to simplify the modelling of the dynamic behaviour of structures [9-11].
Inevitable degradation suffered over years of use by masonry constructions necessitates the periodic assessment for structural integrity to ensure safety, and it can serve as an essential tool to validate the design of new constructions [12]. However, even nowadays, it is a rather difficult task to find a reliable method that would encompass a variety of masonry materials with accuracy proximal to the experimental data [13]. Physical experiments on masonry structures itself are prohibitively expensive which requires significant consumption of material and time. Thus, the amount of available experimental data of masonry structures is sparse and warrants the use of various computational analysis approaches.

The discontinuous and increasingly nonlinear nature of masonry under stress, especially after crack initiation, complicates structural analysis. Broadly, studies of masonry behaviour fall into two approaches, homogeneous and heterogeneous [14]. A homogeneous approach regards masonry as a composite material, and it is used in 
macromodelling to study the overall structural response [15]. It simplifies calculations, but macromodelling cannot properly predict the local behaviour. The heterogeneous approach is used in micromodelling where every masonry component, unit, and mortar are modelled individually. Hence, it is more detailed and realistic but complicated and time-consuming. A homogenization approach stands as an intermediate between macro- and micromodelling that considers masonry as a heterogeneous structure divided into periodic cells. It allows the user to extract a representative element to describe the whole structure $[16,17]$.

Initially, constitutive models with continuum representations were utilized for engineering modelling of masonry yielding acceptable estimations. However, the inhomogeneous composition is better simulated using discontinuous micromodelling approaches, and thus such techniques were frequently used in the past two decades [18-20]. Even so, collating the multitude of compositional and structural variables inside the finite/discrete element method (F/DEM) to solve equations of motions for material deformation, contact point interactions, failure load, and crack propagation remains a daunting task. Many researchers turned to the use of artificial intelligence (AI) techniques to overcome these issues. Among such techniques, neural networks (NNs) have progressively gained popularity due to its ability to solve a wide variety of problems at lower computational costs and simplified approach. However, only a few studies incorporate the use of NNs for the approximation of masonry behaviour in general. Recently, NNs have been successfully used in civil engineering to solve a variety of problems [21-30].

The analysis of panels under biaxial bending is amongst the earliest applications of NNs for the prediction of masonry behaviour [31], which showed the ability of NNs to solve complex nonlinear problems. A multilayer perceptron $\mathrm{NN}$ [32] and a radial basis function NN [33] were able to predict creep deformations in masonry structures showing a relatively small prediction error. Garzón-Roca et al. used NN and fuzzy logic to estimate the axial load and compressive strength of masonry made of clay bricks and cement mortar $[34,35]$. Asteris and Plevris employed a NN to approximate failure for masonry under biaxial stress. They proposed a computational procedure for approximating failure curves in $3 \mathrm{D}$ achieving improved prediction performance and providing valuable information about the influence of different loading angles [36, 37]. Cascardi et al. proposed an artificial NN model to predict the in-plane shear strength of masonry panels strengthened by Fibre Reinforced Polymer systems based on a large experimental database [38, 39].

Another (AI) technique that has gained popularity in resolving problems of masonry structures analysis is cellular automata (CA). CA method for masonry panels is first mentioned by Zhou G. C. in 2002. They applied CA techniques to improve the standard finite element (FE) method used to calculate failure load, proposing a concept of similar zones and strength/stiffness corrector [40]. Zhang et al. applied NN to predict the cracking patterns of masonry walls loaded vertically at different orientations using the CA model and experimental data of the recorded cracking patterns [41]. By harnessing the advantages of CA and finite element analysis (FEA), Huang et al. developed a method for predicting the failure load of masonry wall panels relying on generalized strain-energy density (GSED) extracted from the so-called "base" panel [42]. And later on, Huang et al. used the combination of CA and GSED to map cracking patterns of laterally loaded masonry wall panels with openings based on displacements of CA cells calculated from the FE method and maximum correlation coefficient [43]. In our previous work, a combined NN and CA approach also showed the capacity to effectively predict the crack propagation of masonry panels with openings based on panels' configuration information [44].

This study is focused on the homogenization approach through the investigation of the synergistic effect of NN and a modified CA method to predict failure load of masonry panels, with and without openings, subjected to lateral loading relying on panels' geometric configuration. An opening-centric modified CA method is combined with a $\mathrm{NN}$ that uses a backpropagation algorithm and two hidden layers for modelling. To the best of our knowledge, this is the first report on a combined CA and NN approach for predicting the failure load of masonry panels with openings. The proposed method is verified through comparison with FEA, yield line theory (YL), and GSED methods.

\section{Materials and Methods}

As the geometry variation has a significant effect on the unreinforced masonry resistance to lateral loading [45], masonry panels were modelled as a structure of nine cells defined by the length-height ratio of the cell relative to the openings using the CA theory. Then, the $\mathrm{NN}$ is trained on the obtained CA information and wallette strength (WS) parameter to predict the failure load for the panels.

2.1. Experimental Data. This study is built on the experimental data of 55 masonry wall panels [46]. Of which, 44 are single leaf solid panels and 11 have an opening (Table 1).

The experimental data was randomly divided into three groups: training, testing, and validation by 70,15 , and 15 percent, respectively.

It should be noted that while the amount of the available training data was limited, it is comparable to experimental training data sets used by other researchers in the field $[38,47]$, which proved to be enough to showcase the method for the current problem.

2.2. Cellular Automata. CA can be described as a model of a spatially extended decentralized system made up of a number of individual cells. Each cell is in a specific state which changes over time depending on the state of its local neighbours. CA is a collection of cells that each adapts one of a finite number of states. Single cells change in states by following a local rule that depends on the environment of the cell [48].

Herein, a new generalized CA model was developed using the concept of eight-neighbourhood Moore CA. In 
TABLE 1: Experimental data.

\begin{tabular}{|c|c|c|c|c|c|c|c|c|c|}
\hline Panel & $\begin{array}{l}\text { Length } \\
(\mathrm{m})\end{array}$ & $\begin{array}{l}\text { Height } \\
(\mathrm{m})\end{array}$ & $\begin{array}{c}\text { Thickness } \\
(\mathrm{m})\end{array}$ & $\begin{array}{c}\text { Wallet strength } \\
\left(\mathrm{N} / \mathrm{mm}^{2}\right)\end{array}$ & Panel & $\begin{array}{c}\text { Length } \\
(\mathrm{m})\end{array}$ & $\begin{array}{l}\text { Height } \\
(\mathrm{m})\end{array}$ & $\begin{array}{c}\text { Thickness } \\
(\mathrm{m})\end{array}$ & $\begin{array}{c}\text { Wallet strength } \\
\left(\mathrm{N} / \mathrm{mm}^{2}\right)\end{array}$ \\
\hline 1120 & 2.7 & 1.3 & 0.1025 & 2.44 & 1150 & 5.5 & 2.6 & 0.215 & 1.78 \\
\hline 1135 & 2.7 & 2.6 & 0.1025 & 2.44 & 1153 & 5.5 & 3.6 & 0.215 & 1.78 \\
\hline 1116 & 2.7 & 3.6 & 0.1025 & 2.44 & 1237 & 5.5 & 4.5 & 0.215 & 1.78 \\
\hline 1126 & 3.6 & 2.7 & 0.1025 & 2.44 & 1148 & 2.7 & 2.6 & 0.215 & 1.15 \\
\hline 1190 & 2.7 & 5.2 & 0.1025 & 2.44 & 1211 & 2.7 & 3.6 & 0.215 & 1.15 \\
\hline 1108 & 4.5 & 1.3 & 0.1025 & 2.44 & 1246 & 2.7 & 4.5 & 0.215 & 1.15 \\
\hline 1109 & 4.5 & 3.6 & 0.1025 & 2.44 & 1170 & 4.5 & 2.6 & 0.215 & 1.15 \\
\hline 1187 & 4.5 & 5.2 & 0.1025 & 2.44 & 1178 & 4.5 & 3.6 & 0.215 & 1.15 \\
\hline 1094 & 5.5 & 1.3 & 0.1025 & 2.44 & 1224 & 4.5 & 4.5 & 0.215 & 1.15 \\
\hline 1110 & 5.5 & 1.3 & 0.1025 & 2.44 & 1149 & 5.5 & 2.6 & 0.215 & 1.15 \\
\hline 1095 & 5.5 & 3.6 & 0.1025 & 2.44 & 1162 & 5.5 & 3.6 & 0.215 & 1.15 \\
\hline 1171 & 5.5 & 5.2 & 0.1025 & 2.44 & 1231 & 5.5 & 4.5 & 0.215 & 1.15 \\
\hline 1121 & 2.7 & 1.3 & 0.1025 & 1.19 & ART01 & 4.715 & 2.465 & 0.1025 & 3.2 \\
\hline 1123 & 2.7 & 2.6 & 0.1025 & 1.19 & SB01 & 5.615 & 2.475 & 0.065 & 1.7 \\
\hline 1117 & 2.7 & 3.6 & 0.1025 & 1.19 & SB05 & 5.615 & 2.475 & 0.102 & 1.7 \\
\hline 1203 & 2.7 & 5.2 & 0.1025 & 1.19 & SB06 & 5.615 & 2.475 & 0.065 & 1.7 \\
\hline 1107 & 4.5 & 1.3 & 0.1025 & 1.19 & $\begin{array}{c}\text { Panels with an } \\
\text { opening }\end{array}$ & & & & \\
\hline 1111 & 4.5 & 3.6 & 0.1025 & 1.19 & Panel 1 & 4.84 & 2.475 & 0.1025 & 1.2 \\
\hline 1201 & 4.5 & 5.2 & 0.1025 & 1.19 & Panel 2 & 4.84 & 2.475 & 0.1025 & 1.2 \\
\hline 1096 & 5.5 & 1.3 & 0.1025 & 1.19 & Panel 3 & 4.84 & 2.475 & 0.1025 & 1.2 \\
\hline 1097 & 5.5 & 3.6 & 0.1025 & 1.19 & ART02 & 4.715 & 2.465 & 0.1025 & 3.2 \\
\hline 1157 & 5.5 & 5.2 & 0.1025 & 1.19 & ART03 & 4.715 & 2.465 & 0.1025 & 3.2 \\
\hline 1172 & 2.7 & 2.6 & 0.215 & 1.78 & ART04 & 4.715 & 2.465 & 0.1025 & 3.2 \\
\hline 1192 & 2.7 & 3.6 & 0.215 & 1.78 & ART06 & 4.715 & 2.465 & 0.1025 & 3.2 \\
\hline 1261 & 2.7 & 4.5 & 0.215 & 1.78 & SB02 & 5.615 & 2.475 & 0.065 & 1.7 \\
\hline 1169 & 4.5 & 2.6 & 0.215 & 1.78 & SB03 & 5.615 & 2.475 & 0.065 & 1.7 \\
\hline 1173 & 4.5 & 3.6 & 0.215 & 1.78 & SB04 & 5.615 & 2.475 & 0.065 & 1.7 \\
\hline 1244 & 4.5 & 4.5 & 0.215 & 1.78 & SB07 & 5.615 & 2.475 & 0.065 & 1.7 \\
\hline
\end{tabular}

this opening-centric model, the opening of a panel is imparted with the role of the central cell surrounded by discretized neighbouring cells (Figure 1).

In this method, the CA model for masonry panels is described as a pattern of $3 \times 3$ cells. State values for cells on that model are formed to consider the size effect and the effect of length-height ratio (Figure 2). It describes the percentage of the solid area of the panel that the cell occupies. The dimensions and size of a cell on the CA model relate to the position of an opening. Hence, for the state values $S_{m, n}$ for every cell of a solid masonry, the panel is considered equal as shown in equation (1) (Figure 2(a)). But state values for cells of masonry panels with an opening relate to dimensions of a cell and are calculated by equation (2). Openings and areas outside the CA model have state values equal to zero, such as $S_{2,2}=0$ in Figures 2(b) and 2(c) and $S_{3,1}=S_{3,2}=S_{3,3}=S_{1,2}=0$ in Figure 2(d).

$$
\begin{aligned}
& S_{m, n}=\frac{L_{p}}{3 \cdot L_{p}} \cdot \frac{H_{p}}{3 H_{p}}=\frac{1}{9} \\
& S_{m, n}=\frac{L_{n} \cdot H_{m}}{L_{p} \cdot H_{p}}, \quad m=1,2,3 ; n=1,2,3,
\end{aligned}
$$

where $L_{p}$ and $H_{p}$ are the panel's length (m) and height (m), respectively, and $L_{n}$ and $H_{m}$ are the relative length (m) and height $(\mathrm{m})$ of the CA cell $(m, n)$, respectively.
The size effect for masonry panels is taken into consideration in this way. The information on CA model parameters for masonry panels with openings is given in Table 2.

2.3. Neural Network Application. Artificial neural networks are often described as being a simplified model of a human brain. They consist of neuron layers where different neurons of different layers are connected through applied synaptic weights [49]. The structure of a simple neuron for a backpropagation $\mathrm{NN}$ is shown in Figure 3. There the input $\left(x_{1}, \ldots, x_{i}, \ldots, x_{n}\right)$ is transmitted through a connection where it multiplies its strength by the scalar weight $\left(w_{1, j}, \ldots, w_{i, j}, \ldots, w_{n, j}\right)$. The bias $b_{j}$ of the $j$-neuron is added to the weighted input by the summing function. Then, the activation (transfer) function $\varphi$ uses this sum as its argument. Backpropagation NN usually uses a sigmoid function as the activation function.

The weights and biases of $\mathrm{NN}$ are adjustable scalar parameters. The central principle of $\mathrm{NN}$ is that they can reach some desired behaviour by adjusting weights and biases. And, the network can be trained to solve a particular problem. This ability to solve complicated nonlinear problems incorporating multiple parameters and variables makes NN well-suited for the highly anisotropic properties displayed by masonry structures. In the backpropagation training algorithm, the output values 


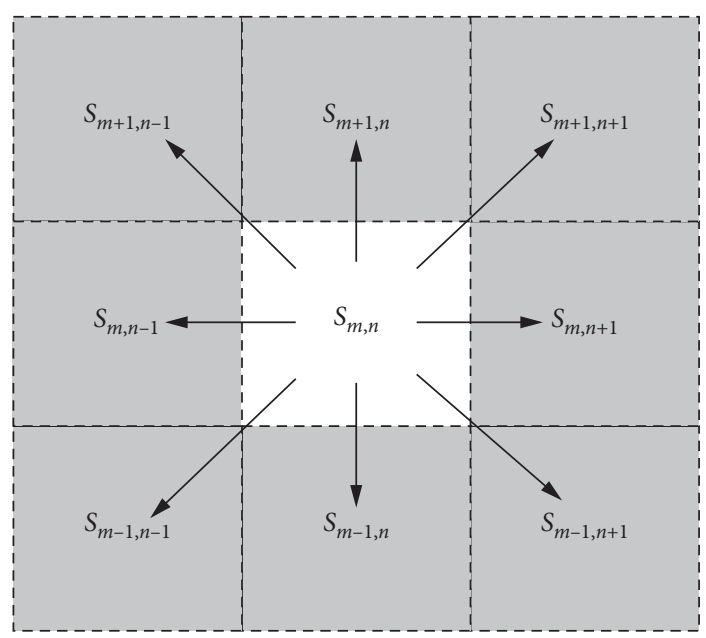

Figure 1: Proposed opening-centric CA model.

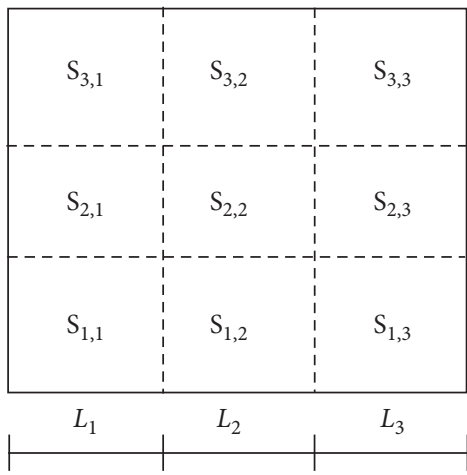

(a)

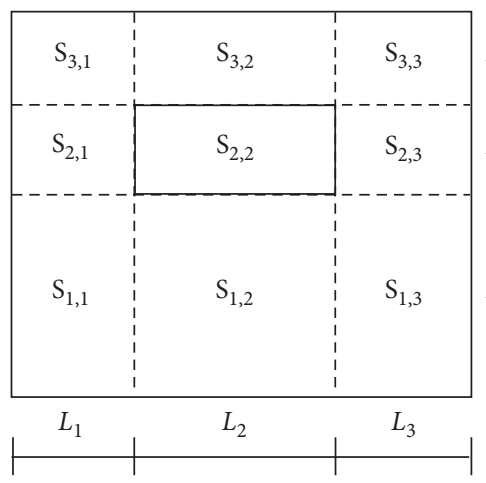

(c)
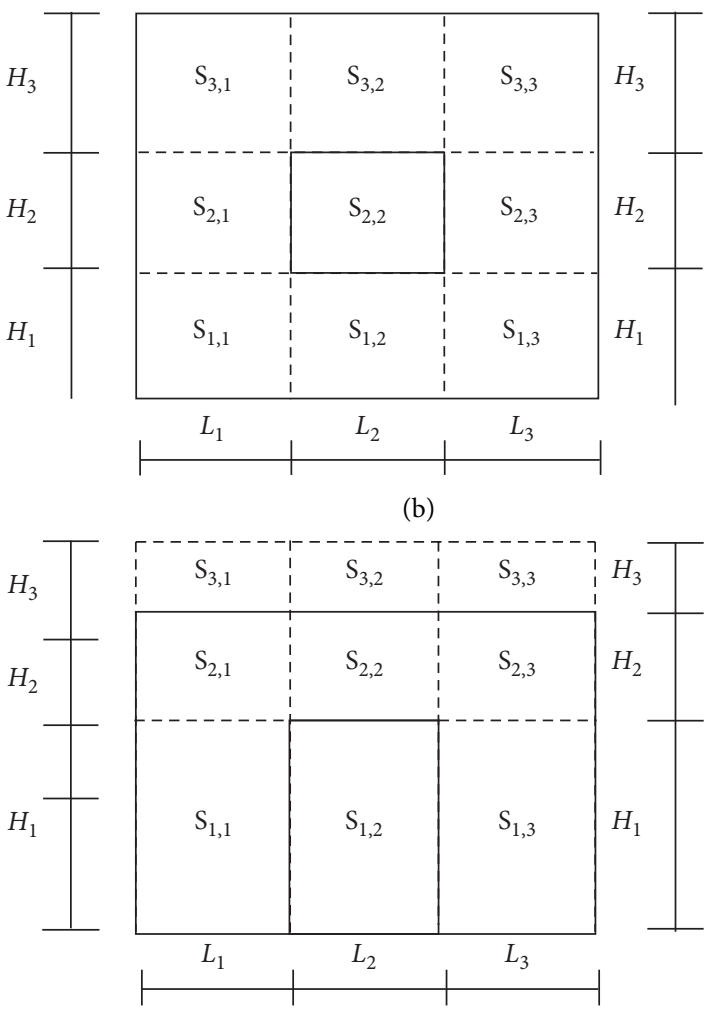

(d)

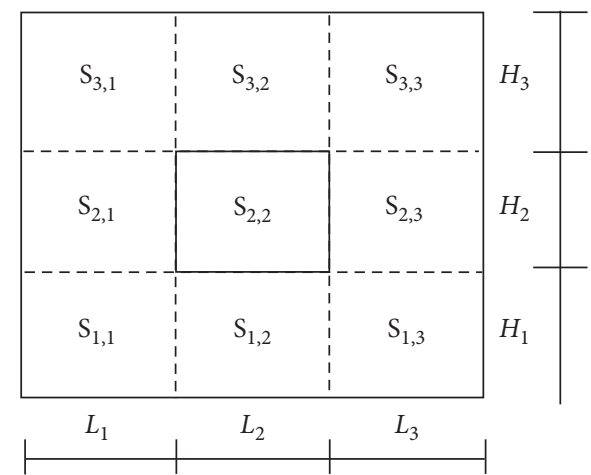

(b)

Figure 2: CA model: (a) for the solid panel and (b), (c), and (d) for panels with an opening according to available experimental data.

calculated by the activation function are compared with the desired output or acceptable convergence. This forms a predefined error function, and the error is then fed back through the network [50]. The algorithm adjusts the weights to reduce the value of the error function in response to this information [51]. This training process repeats until the network reaches a state where the error of the calculations is minimized. 
packages and implementations are optimized to use these options [57]. However, the choice of the training method is constrained by the nature of the problem that needs to be solved with available computational resources [58]. Nonetheless, the difference in speed for small-medium size problems, such as the case of this research, is often marginal and can be ignored with the development of computing technology.

The initialization of weights is a crucial step for backpropagation. The size of the gradient changes relative to the size of the weights. If weights are too small, the gradient becomes too small as well (vanishing gradient problem) and weights can never reach the optimal global minima. This significantly slows down the learning if not prevents the network from learning at all. On the other hand, if the weights are too large, then it leads to an exploding gradient problem when the network keeps learning on the large weights and gradient keeps getting larger, never reaching the convergence point. But if all weights are initialized to zeros, the neurons learn the same features during training and evolve symmetrically unable to learn different features [59]. There are diverse methods to set the initial weights, such as Xavier initialization and He initialization, that change the randomly calculated weights depending on the activation function [60-62]. However, no determined rule would work for all problems. But, stochastic initialization of weights that follows the standard normal distribution is the most used approach. Therefore, both vanishing gradients and exploding gradients are rarely a problem for large networks and modern backpropagation techniques [63].

The NN in this study is trained on two nonlinear layers using feed-forward backpropagation and the efficient Levenberg-Marquardt training algorithm [64-66]. The activation functions for the first hidden layer is the hyperbolic tangent sigmoid function, which returns a matrix of elements in the interval $[-1,1]$, shown in equation (3). The second hidden layer uses the logarithmic-sigmoid activation function (equation (4)). The result's range of this function varies from 0 to 1 . And, the linear activation function is used in the output layer. The number of learning cycles was 1,000 :

$$
\begin{aligned}
& \varphi=\frac{2}{1+e^{-2 x}}-1, \\
& \varphi=\frac{1}{1+e^{-x}} .
\end{aligned}
$$

The most efficient configuration in time/accuracy comparison for the problem was achieved when the number of neurons in the first hidden layer is 11 and neurons in the second hidden layer are 5 (Figure 4).

2.4. Input, Training, and Output Data. Eleven parameters are used as the training data for the NN. Firstly, the panel's configuration coefficient $P$ is considered to describe every calculated CA cell as the part of a masonry panel with a given geometry:
TABLE 2: Configuration of panels with opening according to the CA model.

\begin{tabular}{lcccccc}
\hline Panel & $L_{1}$ & $L_{2}$ & $L_{3}$ & $H_{1}$ & $H_{2}$ & $H_{3}$ \\
\hline Panel 1 & 1.853 & 1.134 & 1.853 & 0.9 & 1.05 & 0.525 \\
Panel 2 & 1.615 & 1.61 & 1.615 & 0.9 & 1.05 & 0.525 \\
Panel 3 & 1.907 & 1.025 & 1.907 & 2.05 & 0.45 & 0 \\
ART02 & 1.565 & 1.585 & 1.565 & 1.04 & 1.06 & 0.365 \\
ART03 & 1.79 & 1.135 & 1.79 & 0.59 & 1.51 & 0.365 \\
ART04 & 1.115 & 2.485 & 1.115 & 1.415 & 0.685 & 0.365 \\
ART06 & 2.465 & 1.585 & 0.665 & 1.04 & 1.06 & 0.365 \\
SB02 & 1.677 & 2.26 & 1.678 & 0.9 & 1.125 & 0.45 \\
SB03 & 1.34 & 2.935 & 1.34 & 1.5 & 0.525 & 0.45 \\
SB04 & 2.352 & 0.91 & 2.353 & 2.025 & 0.45 & 0 \\
SB07 & 1 & 0.9 & 1 & 0.9 & 0.9 & 0.65 \\
\hline
\end{tabular}

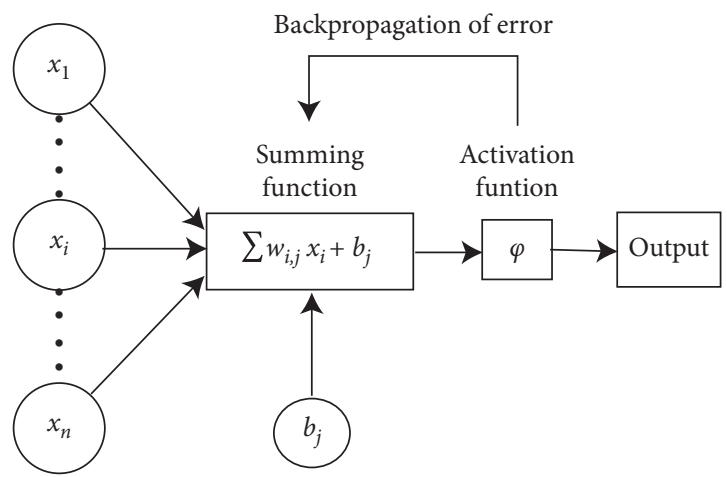

FIGURE 3: Simple neuron model for NN with backpropagation.

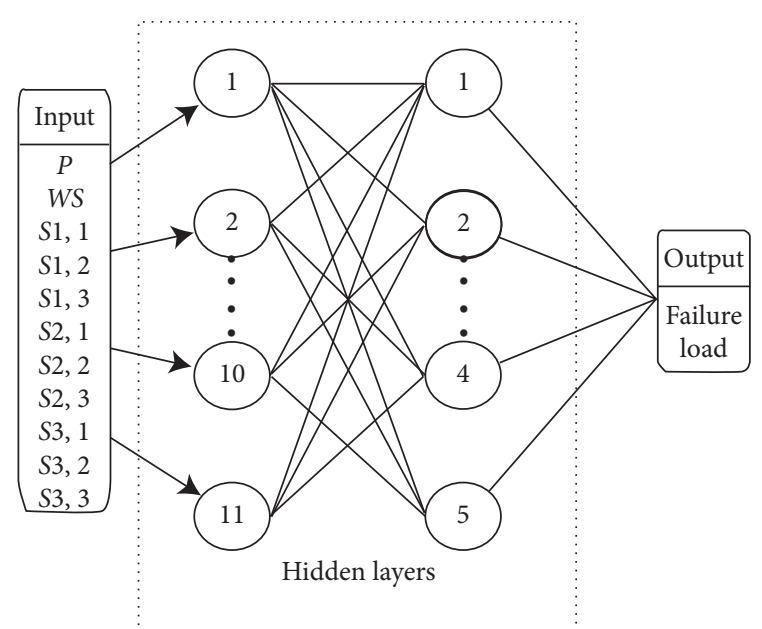

FIgURE 4: Topology of the neural network.

$$
P=\frac{L_{p}}{H_{p}} T_{p}
$$

where $P$ is the panel's configuration coefficient, $L_{p}$ and $H_{p}$ are the panel's length $(\mathrm{m})$ and height $(\mathrm{m})$, respectively, and $T_{p}$ is the panel's thickness (m).

Next, the input parameters are wallet strength $(W S)$ and state values $S_{i, j}$ from equations (1)-(2). Both von Neumann and Moore neighbourhood discretization strategies were 
evaluated, and the latter was found to be more accurate for the given data set and all results presented hereafter are based on it.

The backpropagation algorithm requires the input data to be less than 1 which is suitable for the sigmoid activation function. There are different methods to normalize the input data for backpropagation neural networks [67-69].

It was decided to normalize parameter $P$ through multiplication on $T_{p}$ using several optimization trial experiments.

The output data in the proposed method are vectors of failure load. Those vectors were normalized to match the interval $[0,1]$ using the min-max normalisation method:

$$
g_{\text {out }}=\frac{\left(g_{i}-g_{\min }\right)}{\left(g_{\max }-g_{\min }\right)},
$$

where $g_{\text {out }}$ is the output failure load, $g_{i}$ is the experimental failure load, and $g_{\min }$ and $g_{\max }$ are minimum and maximum failure load equal to 0 and 100 , respectively.

The topology of $\mathrm{NN}$ is shown in Figure 4.

Table 3 contains the example of input data for panels with an opening SB02, Panel 3, and ART06.

\section{Results and Discussion}

Initially, a thousand training epochs were set for the $\mathrm{NN}$ to validate the rationality of the devised approach. However, the training was stopped after the best performance was reached at 363 epochs. The performance, in this case, was calculated by the mean square error for the training output compared with the experimental data.

The results of the training process achieved performance and training regression and are shown in Figure 5.

The predicted results of the NN were compared with the FEA and yield line theory (YL) to evaluate the performance of the proposed method. The YL prediction was built according to the British Standard Institution BS 5628 by Chong V. L. The FEA prediction was also made by Chong V.L. using $8 \times 8 \mathrm{FE}$ mesh. The comparison between predictions made by different methods and experimental failure loads are listed in Table 4. Moreover, the accuracy of the different methods can be seen in Table 5 .

As the micromacro scale variation in masonry structure from one panel to the next makes it a tremendously difficult task to model it analytically, there is a large discrepancy in $\mathrm{NN}, \mathrm{FEA}$, and YL predictions in comparison to experimental data. In this research, two comparative models that fundamentally approach analytical load modelling from different points of scale were used.

YL theory briefly approaches the panel (slab) load prediction from a macroscale level by assuming that the panel behaves like a perfectly plastic structure and develops positive and negative yield lines under an applied overload. It also permits the determination of the ultimate load for a defined collapse mechanism. While the results from the YL method provide reasonable experimental agreement, they tend to overestimate the failure strength. Another drawback of this method is its inability to precisely define the position of openings [46].
TABLE 3: Example of the input data for panels with an opening.

\begin{tabular}{lccc}
\hline Input & SB02 & $\begin{array}{c}\text { Panel } \\
\text { Panel 3 }\end{array}$ & ART06 \\
\hline P & 0.14746 & 0.19840 & 0.09456 \\
WS & 0.17000 & 0.12000 & 0.32000 \\
$S_{1,1}$ & 0.10861 & 0.32315 & 0.45734 \\
$S_{1,2}$ & 0.14636 & 0.00000 & 0.29407 \\
$S_{1,3}$ & 0.10867 & 0.32315 & 0.12338 \\
$S_{2,1}$ & 0.13576 & 0.07094 & 0.46614 \\
$S_{2,2}$ & 0.00000 & 0.03813 & 0.00000 \\
$S_{2,3}$ & 0.13584 & 0.07094 & 0.12575 \\
$S_{3,1}$ & 0.05430 & 0.00000 & 0.16051 \\
$S_{3,2}$ & 0.07318 & 0.00000 & 0.10321 \\
$S_{3,3}$ & 0.05433 & 0.00000 & 0.04330 \\
\hline
\end{tabular}

In comparison, FEA approaches the load prediction problem from the microscale level by allowing the division of panel into many discretized units (elements) and tuning their properties to illustrate the local behaviour. FEA requires the definition of each element's material properties, loading, geometry, location, and relationship with neighbouring elements. However, for heterogeneous structures such as masonry panels, such exhaustive elemental definitions can lead to an exponential increase in the required computing power while offering little flexibility for adapting to different panels.

In this work, we have tried to bridge the gap between FEA and YL modelling techniques by combining the cellular automata discretization and the adaptable learning ability of ANNs. CA allowed the accurate definition of panel structures and opening locations, while the macroscopic panel properties such as wallet strength, length, height, and thickness, are fed as input training data for the NN.

Further evaluation of the method was performed by using different statistical parameters such as the root-meansquared error (RMSE), the mean absolute percentage error (MAPE), the coefficient of determination $\left(R^{2}\right)$, and the integral absolute error (IAE). In theory, the closer the values of RMSE, MAPE, and IAE parameters to zero, the higher the accuracy of the proposed NN. Besides, the closer the $R^{2}$ values to 1 , the greater are the similarities between predicted and experimental failure loads. Parameters RMSE, MAPE, $R^{2}$, and IAE were calculated by equations (7)-(10). Table 6 shows the comparison between FEA, proposed NN, and YL methods based on these statistical parameters. The comparison is calculated for 47 panels for which the YL results are given in Tables 4 and 5 and for all 55 panels studied here for FEA and NN:

$$
\begin{aligned}
\text { RMSE } & =\sqrt{\frac{1}{n} \sum_{i}\left(g_{i}-u_{i}\right)^{2}}, \\
\text { MAPE } & =\frac{1}{n} \sum_{i}\left|\frac{g_{i}-u_{i}}{g_{i}}\right|, \\
R^{2} & =1-\left(\frac{\sum_{i}\left(g_{i}-u_{i}\right)^{2}}{\sum_{i}\left(g_{i}-\bar{g}\right)^{2}}\right),
\end{aligned}
$$




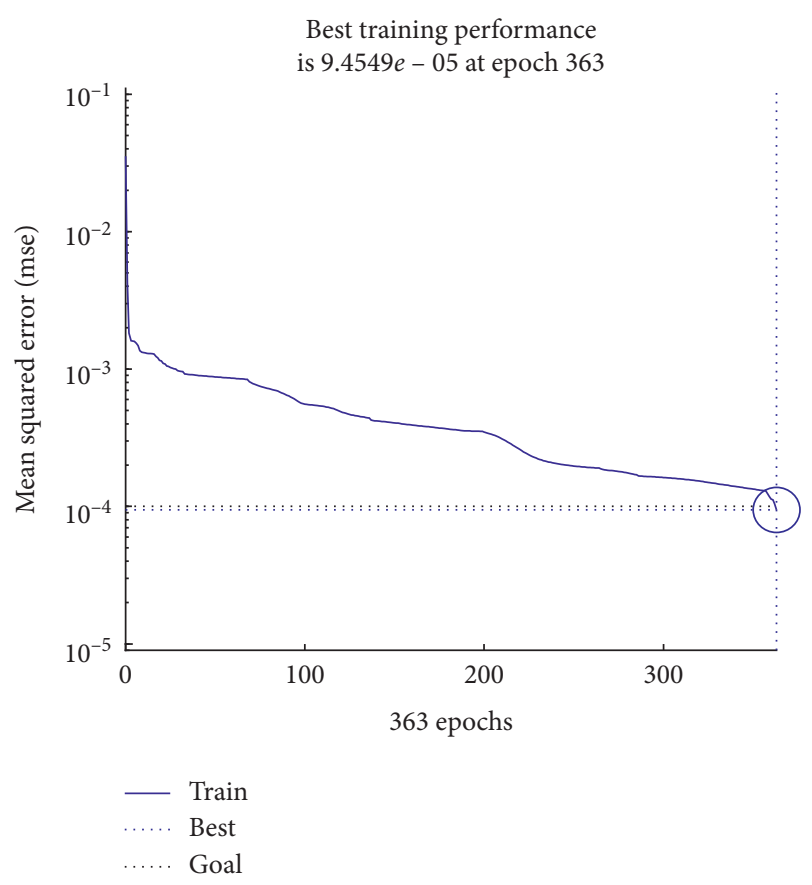

(a)

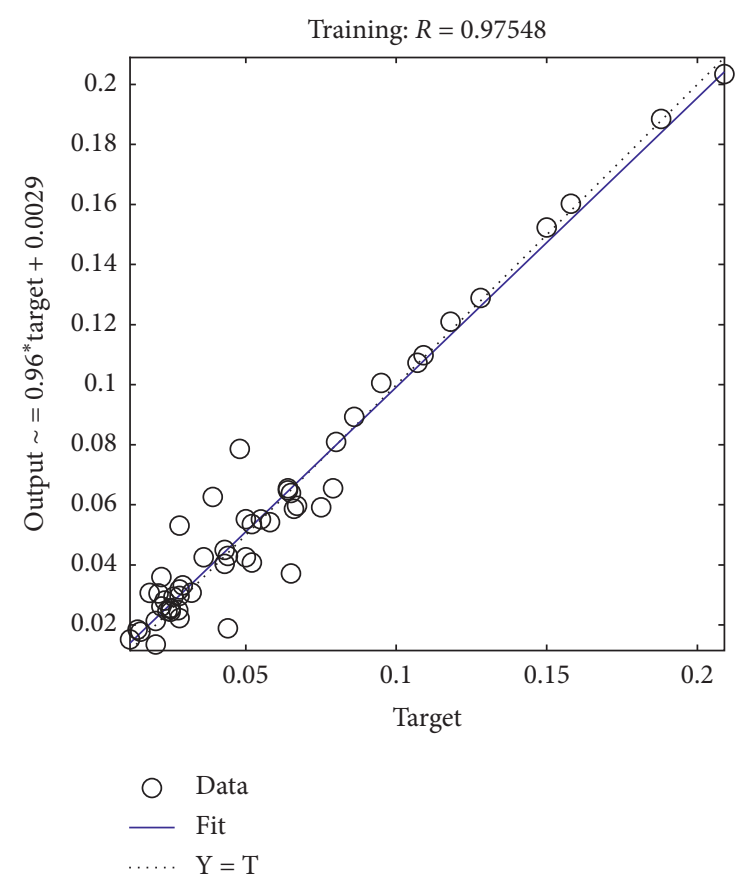

(b)

Figure 5: Training (a) performance and (b) regression.

TABle 4: Comparison between NN, FEA, and YL prediction with the experimental data (Expt.).

\begin{tabular}{|c|c|c|c|c|c|c|c|c|c|}
\hline Panel & Expt. $\left(\mathrm{kN} / \mathrm{m}^{2}\right)$ & $\mathrm{YL}\left(\mathrm{kN} / \mathrm{m}^{2}\right)$ & $\operatorname{FEA}\left(\mathrm{kN} / \mathrm{m}^{2}\right)$ & $\mathrm{NN}\left(\mathrm{kN} / \mathrm{m}^{2}\right)$ & Panel & Expt. $\left(\mathrm{kN} / \mathrm{m}^{2}\right)$ & $\mathrm{YL}\left(\mathrm{kN} / \mathrm{m}^{2}\right)$ & $\operatorname{FEA}\left(\mathrm{kN} / \mathrm{m}^{2}\right)$ & $\mathrm{NN}\left(\mathrm{kN} / \mathrm{m}^{2}\right)$ \\
\hline 1120 & 10.9 & 13.16 & 9.65 & 10.975 & 1150 & 10.7 & 11.05 & 8.83 & 10.727 \\
\hline 1135 & 6.5 & 9.87 & 6.85 & 3.710 & 1153 & 6.7 & 9.06 & 7.04 & 5.973 \\
\hline 1116 & 7.9 & 8.88 & 6.67 & 6.551 & 1237 & 6.5 & 8.24 & 6.2 & 6.406 \\
\hline 1126 & 6.4 & 8.88 & 6.67 & 6.551 & 1148 & 15.8 & 22.09 & 15.37 & 16.057 \\
\hline 1190 & 6.4 & 8.46 & 6.65 & 6.480 & 1211 & 12.8 & 20.25 & 14.9 & 12.900 \\
\hline 1108 & 5.2 & 6.66 & 4.87 & 5.356 & 1246 & 11.8 & 19.29 & 15.09 & 12.103 \\
\hline 1109 & 3.2 & 3.8 & 2.77 & 3.071 & 1170 & 8.6 & 9.96 & 7.53 & 8.938 \\
\hline 1187 & 2.8 & 3.38 & 2.33 & 5.303 & 1178 & 5.2 & 8.76 & 5.93 & 4.087 \\
\hline 1094 & 3.6 & 5.04 & 4.08 & 4.246 & 1224 & 4.8 & 8.11 & 5.49 & 7.872 \\
\hline 1110 & 5 & 5.04 & 4.08 & 4.246 & 1149 & 6.6 & 7.7 & 5.63 & 5.864 \\
\hline 1095 & 2.9 & 2.77 & 1.95 & 3.317 & 1162 & 4.3 & 6.37 & 4.5 & 4.504 \\
\hline 1171 & 2.2 & 2.41 & 1.67 & 3.593 & 1231 & 3.9 & 5.86 & 3.92 & 6.272 \\
\hline 1121 & 5.8 & 6.88 & 4.69 & 5.424 & ART01 & 4.4 & - & 4.56 & 4.290 \\
\hline 1123 & 4.4 & 5.35 & 3.04 & 1.887 & SB01 & 2.8 & 3.164 & 2.464 & 2.968 \\
\hline 1117 & 4.3 & 4.98 & 3.02 & 4.030 & SB05 & 2.7 & 3.159 & 2.457 & 3.184 \\
\hline 1203 & 3.4 & 4.74 & 2.97 & 2.580 & Panels with an opening & & & & \\
\hline 1107 & 5 & 3.43 & 2.31 & 5.530 & SB06 & 7.5 & 8.7 & 6.75 & 5.920 \\
\hline 1111 & 4.3 & 2.06 & 1.17 & 2.528 & Panel 1 & 1.5 & - & 1.31 & 1.769 \\
\hline 1201 & 2.1 & 1.87 & 1.01 & 3.044 & Panel 2 & 1.2 & - & 1.22 & 1.503 \\
\hline 1096 & 2.8 & 1.65 & 1.89 & 2.227 & Panel 3 & 2 & - & 1.24 & 2.125 \\
\hline 1097 & 1.8 & 1.5 & 0.91 & 3.067 & ART02 & 2.75 & - & 2.39 & 2.487 \\
\hline 1157 & 1.4 & 1.35 & 0.73 & 1.840 & ART03 & 2.6 & - & 2.6 & 2.933 \\
\hline 1172 & 20.9 & 31.35 & 23.75 & 20.372 & ART04 & 2.5 & - & 2.21 & 2.557 \\
\hline 1192 & 18.8 & 28.08 & 23.6 & 18.862 & ART06 & 2.5 & - & 2.69 & 2.437 \\
\hline 1261 & 15 & 27.26 & 23.59 & 15.238 & SB02 & 2.4 & 2.592 & 1.824 & 2.461 \\
\hline 1169 & 9.5 & 14.4 & 11.66 & 10.059 & SB03 & 2.3 & 2.438 & 1.587 & 2.478 \\
\hline 1173 & 8 & 12.31 & 9.49 & 5.274 & SB04 & 2.2 & 2.574 & 1.804 & 2.602 \\
\hline 1244 & 8 & 11.28 & 8.63 & 8.112 & SB07 & 5.5 & 6.985 & 5.17 & 5.514 \\
\hline
\end{tabular}


TABLE 5: Comparison between NN, FEA, and YL accuracy of prediction.

\begin{tabular}{|c|c|c|c|c|c|c|c|}
\hline Panel & YL error (\%) & FEA error (\%) & NN error $(\%)$ & Panel & YL error (\%) & FEA error (\%) & NN error (\%) \\
\hline 1120 & 20.73 & 11.47 & 0.69 & 1150 & 3.27 & 17.48 & 0.26 \\
\hline 1135 & 51.85 & 5.38 & 42.92 & 1153 & 35.22 & 5.07 & 10.86 \\
\hline 1116 & 12.41 & 15.57 & 17.08 & 1237 & 26.77 & 4.62 & 1.44 \\
\hline 1126 & 38.75 & 4.22 & 2.36 & 1148 & 39.81 & 2.72 & 1.63 \\
\hline 1190 & 32.19 & 3.91 & 1.26 & 1211 & 58.20 & 16.41 & 0.78 \\
\hline 1108 & 28.08 & 6.35 & 3.00 & 1246 & 63.47 & 27.88 & 2.57 \\
\hline 1109 & 18.75 & 13.44 & 4.03 & 1170 & 15.81 & 12.44 & 3.93 \\
\hline 1187 & 20.71 & 16.79 & 89.39 & 1178 & 68.46 & 14.04 & 21.40 \\
\hline 1094 & 40.00 & 13.33 & 17.93 & 1224 & 68.96 & 14.38 & 64.00 \\
\hline 1110 & 0.80 & 18.40 & 15.09 & 1149 & 16.67 & 14.70 & 11.15 \\
\hline 1095 & 4.48 & 32.76 & 14.37 & 1162 & 48.14 & 4.65 & 4.74 \\
\hline 1171 & 9.55 & 24.09 & 63.32 & 1231 & 50.26 & 0.51 & 60.82 \\
\hline 1121 & 18.62 & 19.14 & 6.48 & ART01 & - & 3.64 & 2.50 \\
\hline 1123 & 21.59 & 30.91 & 57.11 & SB01 & 13 & 12.00 & 6.01 \\
\hline 1117 & 15.81 & 29.77 & 6.27 & SB05 & 17 & 9.00 & 17.93 \\
\hline 1203 & 39.41 & 12.65 & 24.12 & SB06 & 16 & 10.00 & 21.06 \\
\hline 1107 & 31.40 & 53.80 & 10.59 & Panels with an opening & & & \\
\hline 1111 & 52.09 & 72.79 & 41.22 & Panel 1 & - & 12.67 & 17.95 \\
\hline 1201 & 10.95 & 51.90 & 44.98 & Panel 2 & - & 1.67 & 25.29 \\
\hline 1096 & 41.07 & 32.50 & 20.47 & Panel 3 & - & 38.00 & 6.26 \\
\hline 1097 & 16.67 & 49.44 & 70.38 & ART02 & - & 13.09 & 9.57 \\
\hline 1157 & 3.57 & 47.86 & 31.44 & ART03 & - & 0.00 & 12.79 \\
\hline 1172 & 50.00 & 13.64 & 2.53 & ART04 & - & 11.60 & 2.29 \\
\hline 1192 & 49.36 & 25.53 & 0.33 & ART06 & - & 7.60 & 2.53 \\
\hline 1261 & 81.73 & 57.27 & 1.59 & SB02 & 8 & 24.00 & 2.55 \\
\hline 1169 & 51.58 & 22.74 & 5.89 & SB03 & 6 & 31.00 & 7.74 \\
\hline 1173 & 53.88 & 18.63 & 34.07 & SB04 & 17 & 18.00 & 18.26 \\
\hline 1244 & 41.00 & 7.88 & 1.40 & SB07 & 27 & 6.00 & 0.25 \\
\hline
\end{tabular}

TABLE 6: Statistical analysis of failure load prediction between YL, FEA, and NN methods.

\begin{tabular}{lcccccrrr}
\hline \multirow{2}{*}{ Method } & \multicolumn{2}{c}{ RMSE } & \multicolumn{2}{c}{ MAPE } & \multicolumn{2}{c}{$R^{2}$} & \multicolumn{2}{c}{ IAE (\%) } \\
& I & II & I & II & I & II & II \\
\hline YL & 3.70141 & - & 0.30980 & - & 0.29780 & - & 37.44 & - \\
FEA & 1.88856 & 1.75044 & 0.20362 & 0.19005 & 0.81719 & 0.83673 & 18.86 \\
NN & 1.14336 & 1.06020 & 0.18886 & 0.17579 & 0.933 & 0.94011 & 12.07 \\
\hline
\end{tabular}

Note: I, calculated for 47 panels with YL; II, calculated for all 55 panels without YL.

$$
\mathrm{IAE}=\frac{\sum_{i}\left|g_{i}-u_{i}\right|}{\sum_{i} g_{i}} \cdot 100 \%
$$

where $n$ is the number of tested panels, $g_{i}$ is the experimental failure load, $u_{i}$ is the predicted failure load, and $\bar{g}$ is the average experimental failure load.

It was observed that for more than $75 \%$ of the panels the percentage error was smaller than $20 \%$. Especially for the panels with an opening where all panels had an error deviation below $20 \%$. The low accuracy of the prediction for a few panels can be explained by the fact that prediction in this case significantly depends on the WS parameter, limited training data, and possible variations in the experimental process. Overall, it is safe to assume that the optimized NN was able to outperform FEA and YL.

Figure 6 compares the results of NN and FEA prediction to the experimental data. While both methods can offer comparable accuracy for panels with low experimental failure loads, the error variation range for masonry panels with failure loads more than $10 \mathrm{kN} / \mathrm{m}^{2}$ is lower and significantly more accurate using the $\mathrm{NN}$ prediction.

In addition, the proposed method is compared with the GSED method proposed by Huang and based on CA and FEA [42]. Huang et al. used the strain-energy density of a known (base) panel and a new (to be predicted) panel and a criterion for matching zone similarities to calculate failure load for masonry panels.

Although the results from GSED and NN give a good prediction for failure load, a closer inspection reveals that in all cases except one, the percentage error is smaller for $\mathrm{NN}$ as compared with GSED results (Table 7).

An additional drawback of the GSED method is that its accuracy depends on the base panel used for prediction. Hence, it is crucial to have experimental information for a panel with a similar condition to the predicted panel. Besides, the NN prediction can be calculated regardless of the 


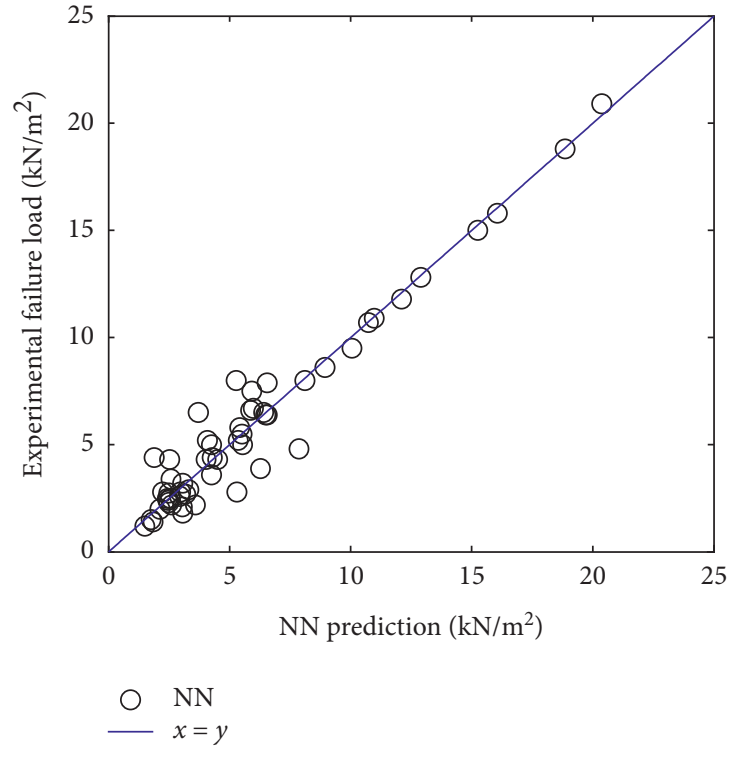

(a)

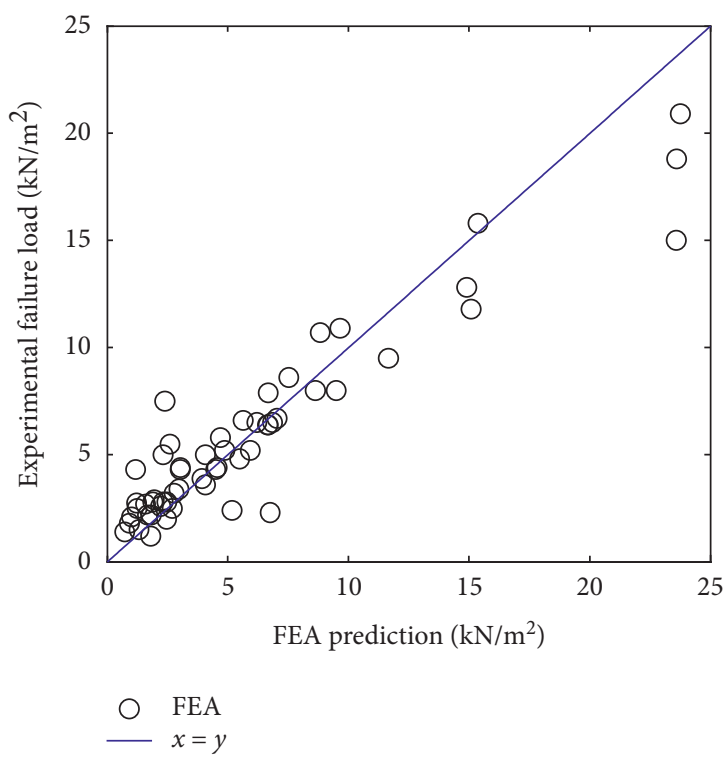

(b)

FIgURE 6: Comparison of (a) the NN and (b) FEA prediction with the experimental failure load. The $x=y$ line represents the ideal state when predicted results are equal to the experimental failure load.

TABLe 7: Comparison between proposed NN and GSED methods (two panels (1173 and 1172) are used in the GSED method as the base on which the prediction is built).

\begin{tabular}{cccccc}
\hline Panel & \multicolumn{2}{c}{ Failure load $\left(\mathrm{kN} / \mathrm{m}^{2}\right)$} & Error (\%) \\
\hline & Expt. & GSED $(1173$ based $)$ & $\mathrm{NN}$ & GSED $(1173$ based $)$ & $\mathrm{NN}$ \\
1172 & 20.9 & 20.01 & 20.372 & 4.26 & 2.53 \\
1169 & 9.5 & 12.53 & 10.059 & 31.89 & 5.89 \\
1244 & 8 & 6.42 & 8.112 & 19.75 & 1.40 \\
1150 & 10.7 & 10.36 & 10.727 & 2.9 & 0.26 \\
1153 & 6.7 & 7.03 & 5.973 & 4.93 & 10.86 \\
1237 & 6.5 & 5.3 & 6.406 & 18.46 & 1.44 \\
\hline & Expt. & GSED $(1172$ based $)$ & $\mathrm{NN}$ & GSED $(1172$ based $)$ & $\mathrm{NN}$ \\
1169 & 9.5 & 13.6 & 10.059 & 43.16 & 5.89 \\
1244 & 8 & 7.13 & 8.112 & 10.88 & 1.40 \\
1150 & 10.7 & 11.23 & 10.727 & 4.95 & 0.26 \\
1153 & 6.7 & 7.73 & 5.973 & 15.37 & 10.86 \\
1237 & 6.5 & 5.9 & 6.406 & 9.23 & 1.44 \\
\hline
\end{tabular}

configuration of the new (predicted) panel. NN can be trained on available experimental data to calculate failure load for panels with any configuration.

\section{Conclusions}

In this study, the backpropagation $\mathrm{NN}$ with two hidden layers is developed to accurately predict the failure load of masonry panels subjected to lateral loading based on panels' configuration and WS. An additional input parameter, panels' configuration coefficient $P$, calculated through length, height, and thickness of the panel, is introduced. This parameter together with WS and discretized cell locations is used as the input training data for the neural network. The modified CA technique is used to realize the state values of the cells where the central cell representing the opening in the panel is fixed. The most efficient configuration for the algorithm programmed for the NN was achieved when using the tangent-sigmoid activation function for the first hidden layer and logarithmic-sigmoid activation function for the second hidden layer with 11 and 5 neurons in the layers, respectively. It is shown that NNs can predict failure load for masonry panels based only on the panel's configuration information. But, the accuracy and comprehensiveness of the network deeply depend on the training data. The results were compared with other well-established methods, and judging by RMSE, MAPE, $R^{2}$, and IAE statistical parameters NN prediction excels the prediction accuracy of FEA and YL analysis by every parameter. While GSED and NN offered effective failure load prediction capability, the $\mathrm{NN}$ is found to be more accurate and general in its applicability.

Even though the proposed method has only been used to validate the experimental data used in this research, an increase in the training data for NN should allow for further refinement of its achieved results. Anyway, the proposed method can provide an additional tool for predicting failure loads and complement other methods like FEA and GSED for in-depth structural analysis. An inherent advantage of the neural modelling method over traditional numerical techniques is that it implicitly identifies and extracts the different characteristics of the panels, including their nonlinear material properties, without requiring explicit and rigorous mathematical expressions, enabling a simplification in numerical modelling and computational cost of masonry.

\section{Data Availability}

The code for neural network and relative weights and biases used to support the findings of this study are available from the corresponding author upon request. 


\section{Conflicts of Interest}

The authors declare that there are no conflicts of interest regarding the publication of this paper.

\section{Acknowledgments}

The authors would like to thank the Chinese Scholarship Council (CSC) for the PhD scholarship.

\section{References}

[1] B. Haseltine, "The evolution of the design and construction of masonry buildings in the UK," Gestão \& Tecnologia de Projetos, vol. 7, no. 2, pp. 20-26, 2012.

[2] M. Xu, J. Huang, C. Wang, and Y. Li, "Fuzzy identification of dynamic loads in presence of structural epistemic uncertainties," Computer Methods in Applied Mechanics and Engineering, vol. 360, Article ID 112718, 2020.

[3] Y. Liu and W. S. Shepard, "Dynamic force identification based on enhanced least squares and total least-squares schemes in the frequency domain," Journal of Sound and Vibration, vol. 282, no. 1-2, pp. 37-60, 2005.

[4] A. N. Thite and D. J. Thompson, "The quantification of structure-borne transmission paths by inverse methods. Part 2: use of regularization techniques," Journal of Sound and Vibration, vol. 264, no. 2, pp. 433-451, 2003.

[5] G. R. Liu, W. B. Ma, and X. Han, "An inverse procedure for identification of loads on composite laminates," Composites Part B: Engineering, vol. 33, no. 6, pp. 425-432, 2002.

[6] F. E. Gunawan, H. Homma, and Y. Kanto, "Two-step B-splines regularization method for solving an ill-posed problem of impact-force reconstruction," Journal of Sound and Vibration, vol. 297, no. 1-2, pp. 200-214, 2006.

[7] M. Pathirana, N. Lam, S. Perera, L. Zhang, D. Ruan, and E. Gad, "Risks of failure of annealed glass panels subject to point contact actions," International Journal of Solids and Structures, vol. 129, pp. 177-194, 2017.

[8] S. Jeong, H. K. Seong, C. W. Kim, and J. Yoo, "Structural design considering the uncertainty of load positions using the phase field design method," Finite Elements in Analysis and Design, vol. 161, pp. 1-15, 2019.

[9] Y. Yang, N. T. K. Lam, and L. Zhang, "Evaluation of simplified methods of estimating beam responses to impact," International Journal of Structural Stability and Dynamics, vol. 12, no. 3, Article ID 1250016, 2012.

[10] J. Sun, N. Lam, L. Zhang, D. Ruan, and E. Gad, "Contact forces generated by hailstone impact," International Journal of Impact Engineering, vol. 84, pp. 145-158, 2015.

[11] J. Mazars and S. Grange, "Simplified strategies based on damage mechanics for concrete under dynamic loading," Philosophical Transactions of the Royal Society A: Mathematical, Physical and Engineering Sciences, vol. 375, no. 2085, Article ID 20160170, 2017.

[12] P. Roca, M. Cervera, G. Gariup, and L. Pela', 'Structural analysis of masonry historical constructions. Classical and advanced approaches," Archives of Computational Methods in Engineering, vol. 17, no. 3, pp. 299-325, 2010.

[13] F. Ferretti, B. Ferracuti, C. Mazzotti, and M. Savoia, "Destructive and minor destructive tests on masonry buildings: experimental results and comparison between shear failure criteria," Construction and Building Materials, vol. 199, pp. 12-29, 2019.
[14] S. Komurcu and A. Gedikli, "Macro and micro modeling of the unreinforced masonry shear walls," European Journal of Engineering and Natural Sciences, vol. 3, pp. 116-123, 2019.

[15] H. O. Koksal, B. Doran, A. O. Kuruscu, and A. Kocak, "Elastoplastic Finite Element analysis of masonry shear walls," KSCE Journal of Civil Engineering, vol. 20, no. 2, pp. 784-791, 2016.

[16] S. Casolo and G. Milani, "A simplified homogenization-discrete element model for the non-linear static analysis of masonry walls out-of-plane loaded," Engineering Structures, vol. 32, no. 8, pp. 2352-2366, 2010.

[17] G. Milani, "Simple homogenization model for the non-linear analysis of in-plane loaded masonry walls," Computers \& Structures, vol. 89, no. 17-18, pp. 1586-1601, 2011.

[18] F. Portioli, C. Casapulla, M. Gilbert, and L. Cascini, "Limit analysis of 3D masonry block structures with non-associative frictional joints using cone programming," Computers \& Structures, vol. 143, pp. 108-121, 2014.

[19] S. Calderón, "Cristián Sandoval and Oriol Arnau, "Shear response of partially-grouted reinforced masonry walls with a central opening: testing and detailed micro-modelling," Materials \& Design, vol. 118, pp. 122-137, 2017.

[20] V. Koç and Y. Emiroğlu, "Examining the behaviour of a reinforced concrete system under horizontal loads and determination of preliminary design reinforcement ratios," International Journal of Civil Engineering, vol. 15, no. 7, pp. 1035-1052, 2017.

[21] M. H. Baziar and Y. Jafarian, "Assessment of liquefaction triggering using strain energy concept and ANN model: capacity energy," Soil Dynamics and Earthquake Engineering, vol. 27, no. 12, pp. 1056-1072, 2007.

[22] A. Panakkat and H. Adeli, "Recurrent neural network for approximate earthquake time and location prediction using multiple seismicity indicators," Computer-Aided Civil and Infrastructure Engineering, vol. 24, no. 4, pp. 280-292, 2009.

[23] H. Erdem, "Prediction of the moment capacity of reinforced concrete slabs in fire using artificial neural networks," Advances in Engineering Software, vol. 41, no. 2, pp. 270-276, 2010.

[24] T. Nishikawa, J. Yoshida, T. Sugiyama, and Y. Fujino, "Concrete crack detection by multiple sequential image filtering," Computer-Aided Civil and Infrastructure Engineering, vol. 27, no. 1, pp. 29-47, 2011.

[25] A. Joghataie and M. S. Dizaji, "Designing high-precision fast nonlinear dam neuro-modelers and comparison with finiteelement analysis," Journal of Engineering Mechanics, vol. 139, no. 10, pp. 1311-1324, 2013.

[26] Z. H. Duan, S. C. Kou, and C. S. Poon, "Using artificial neural networks for predicting the elastic modulus of recycled aggregate concrete," Construction and Building Materials, vol. 44, pp. 524-532, 2013.

[27] M. Gul, F. N. Catbas, and H. Hattori, "Image-based monitoring of open gears of movable bridges for condition assessment and maintenance decision making," Journal of Computing in Civil Engineering, vol. 29, no. 2, Article ID 4014034, 2015.

[28] M. Nikoo, F. Torabian Moghadam, and Ł. Sadowski, "Prediction of concrete compressive strength by evolutionary artificial neural networks," Advances in Materials Science and Engineering, vol. 2015, Article ID 849126, 8 pages, 2015.

[29] P. G. Asteris, K. G. Kolovos, M. G. Douvika, and K. Roinos, "Prediction of self-compacting concrete strength using artificial neural networks," European Journal of Environmental and Civil Engineering, vol. 20, no. sup1, pp. s102-s122, 2016. 
[30] N. Wang, Q. Zhao, S. Li, X. Zhao, and P. Zhao, "Damage classification for masonry historic structures using convolutional neural networks based on still images," ComputerAided Civil and Infrastructure Engineering, vol. 33, no. 12, pp. 1073-1089, 2018.

[31] A. Mathew, B. Kumar, B. P. Sinha, and R. F. Pedreschi, "Analysis of masonry panel under biaxial bending using ANNs and CBR," Journal of Computing in Civil Engineering, vol. 13, no. 3, pp. 170-177, 1999.

[32] M. M. R. Taha, A. Noureldin, N. El-Sheimy, and N. G. Shrive, "Artificial neural networks for predicting creep with an example application to structural masonry," Canadian Journal of Civil Engineering, vol. 30, no. 3, pp. 523-532, 2003.

[33] A. El-Shafie, T. Abdelazim, and A. Noureldin, "Neural network modeling of time-dependent creep deformations in masonry structures," Neural Computing and Applications, vol. 19, no. 4, pp. 583-594, 2010.

[34] J. Garzón-Roca, J. M. Adam, C. Sandoval, and P. Roca, "Estimation of the axial behaviour of masonry walls based on artificial neural networks," Computers \& Structures, vol. 125, pp. 145-152, 2013.

[35] J. Garzón-Roca, C. O. Marco, and J. M. Adam, "Compressive strength of masonry made of clay bricks and cement mortar: estimation based on neural networks and fuzzy logic," Engineering Structures, vol. 48, pp. 21-27, 2013.

[36] P. G. Asteris and V. Plevris, "Neural network approximation of the masonry failure under biaxial compressive stress," in Proceedings of the SEECCM III 3rd South-East European Conference on Computational Mechanics, pp. 12-14, Kos Island, Greece, June 2013.

[37] V. Plevris and P. G. Asteris, "Modeling of masonry failure surface under biaxial compressive stress using Neural Networks," Construction and Building Materials, vol. 55, pp. 447-461, 2014.

[38] A. Cascardi, F. Micelli, and M. A. Aiello, "Analytical model based on artificial neural network for masonry shear walls strengthened with FRM systems," Composites Part B: Engineering, vol. 95, pp. 252-263, 2016.

[39] A. Cascardi, F. Micelli, and M. A. Aiello, "An artificial neural networks model for the prediction of the compressive strength of FRP-confined concrete circular columns," Engineering Structures, vol. 140, pp. 199-208, 2017.

[40] G. C. Zhou, M. Y. Rafiq, G. Bugmann, and D. J. Easterbrook, "Cellular automata model for predicting the failure pattern of laterally loaded masonry wall panels," Journal of Computing in Civil Engineering, vol. 20, no. 6, pp. 400-409, 2006.

[41] Y. Zhang, G. C. Zhou, Y. Xiong, and M. Y. Rafiq, "Techniques for predicting cracking pattern of masonry wallet using artificial neural networks and cellular automata," Journal of Computing in Civil Engineering, vol. 24, no. 2, pp. 161-172, 2010.

[42] Y. Huang, Y. Zhang, M. Zhang, and G. Zhou, "Method for predicting the failure load of masonry wall panels based on generalized strain-energy density," Journal of Engineering Mechanics, vol. 140, no. 8, Article ID 04014061, 2014.

[43] Y. Huang, Y. Zhang, M. Zhang, C. Lv, and G. Zhou, "Cellular automata method for mapping cracking patterns of laterally loaded wall panels with openings," Engineering Review, vol. 35 , no. 1 , pp. 81-88, 2015.

[44] I. Glushakova, Y. Zhang, and G. Zhou, "Application of deeplearning neural networks for mapping cracking patterns of masonry panels with openings," in Proceedings of the 13th Canadian Masonry Symposium, Article ID 102, Vancouver, Canada, June 2017.
[45] J. Park, "Investigation of the geometric variation effect on seismic performance of low-rise unreinforced masonry structures through fragility analysis," International Journal of Civil Engineering, vol. 16, no. 1, pp. 93-106, 2016.

[46] V. L. Chong, The Behaviour of Laterally Loaded Masonry Panels with Openings, University of Plymouth, 1993.

[47] Q. Zhou, F. Zhu, X. Yang, F. Wang, B. Chi, and Z. Zhang, "Shear capacity estimation of fully grouted reinforced concrete masonry walls using neural network and adaptive neurofuzzy inference system models," Construction and Building Materials, vol. 153, pp. 937-947, 2017.

[48] F. Berto and J. Tagliabue, "Cellular automata," in The Stanford Encyclopedia of Philosophy, Fall 2017., E. N. Zalta, Ed., Metaphysics Research Lab, Stanford University, Stanford, CA, USA, 2017.

[49] D. J. Norris, "Machine learning: deep learning," in Beginning Artificial Intelligence with the Raspberry Pi, pp. 211-247, Apress, New York, NY, USA, 2017.

[50] V. Rashidian and M. Hassanlourad, "Application of an artificial neural network for modeling the mechanical behavior of carbonate soils," International Journal of Geomechanics, vol. 14, no. 1, pp. 142-150, 2014.

[51] Q. Zhou, F. Wang, and F. Zhu, "Estimation of compressive strength of hollow concrete masonry prisms using artificial neural networks and adaptive neuro-fuzzy inference systems," Construction and Building Materials, vol. 125, pp. 417-426, October 2016.

[52] N. M. Nawi, R. S. Ransing, M. N. M. Salleh, R. Ghazali, and N. A. Hamid, "An improved back propagation neural network algorithm on classification problems," in Database Theory and Application, pp. 177-188, Bio-Science and Bio-Technology, Berlin, Germany, 2010.

[53] N. M. Nawi, A. Khan, and M. Z. Rehman, "A new Levenberg marquardt based back propagation algorithm trained with cuckoo search," Procedia Technology, vol. 11, pp. 18-23, 2013.

[54] M. Otair and A. S. Walid, "Speeding up back-propagation neural networks," Proceedings of the 2005 Informing Science and IT Education Joint Conference, vol. 1, 2005.

[55] D. Krotov and J. J. Hopfield, "Unsupervised learning by competing hidden units," Proceedings of the National Academy of Sciences, vol. 116, no. 16, pp. 7723-7731, 2019.

[56] D. Masters and C. Luschi, "Revisiting small batch training for deep neural networks," 2018, https://arxiv.org/abs/1804. 07612.

[57] I. H. Witten, E. Frank, M. A. Hall, and C. J. Pal, "Deep learning," in Data Mining, pp. 417-466, Elsevier, Amsterdam, Netherlands, 2017.

[58] D. V. Raman, A. P. Rotondo, and T. O’Leary, "Fundamental bounds on learning performance in neural circuits," Proceedings of the National Academy of Sciences, vol. 116, no. 21, pp. 10537-10546, 2019.

[59] X. Glorot and Y. Bengio, "Understanding the difficulty of training deep feedforward neural networks," Proceedings of the Thirteenth International Conference on Artificial Intelligence and Statistics, vol. 9, pp. 249-256, 2010.

[60] K. He, X. Zhang, S. Ren, and J. Sun, "Delving deep into rectifiers: surpassing human-level performance on ImageNet classification,” 2015, https://arxiv.org/abs/1502.01852.

[61] P. Dolezel, P. Skrabanek, and L. Gago, "Weight initialization possibilities for feedforward neural network with linear saturated activation functions," IFAC-PapersOnLine, vol. 49, no. 25 , pp. 49-54, 2016. 
[62] J. Qiao, S. Li, and W. Li, "Mutual information based weight initialization method for sigmoidal feedforward neural networks," Neurocomputing, vol. 207, pp. 676-683, 2016.

[63] Y. LeCun, Y. Bengio, and G. Hinton, "Deep learning," Nature, vol. 521, no. 7553, pp. 436-444, 2015.

[64] B. M. Wilamowski and H. Hao Yu, "Improved computation for levenberg-marquardt training," IEEE Transactions on Neural Networks, vol. 21, no. 6, pp. 930-937, 2010.

[65] E. M. Golafshani, A. Rahai, M. H. Sebt, and H. Akbarpour, "Prediction of bond strength of spliced steel bars in concrete using artificial neural network and fuzzy logic," Construction and Building Materials, vol. 36, pp. 411-418, 2012.

[66] T.-H. Tran and N.-D. Hoang, "Predicting colonization growth of algae on mortar surface with artificial neural network," Journal of Computing in Civil Engineering, vol. 30, no. 6, Article ID 04016030, 2016.

[67] G. Zhou, D. Pan, X. Xu, and Y. M. Rafiq, "Innovative ANN technique for predicting failure/cracking load of masonry wall panel under lateral load," Journal of Computing in Civil Engineering, vol. 24, no. 4, pp. 377-387, 2010.

[68] U. Naik and S. Kute, "Span-to-depth ratio effect on shear strength of steel fiber-reinforced high-strength concrete deep beams using ANN model," International Journal of Advanced Structural Engineering, vol. 5, no. 1, p. 29, 2013.

[69] M. AlHamaydeh, I. Choudhary, and K. Assaleh, "Virtual testing of buckling-restrained braces via nonlinear autoregressive exogenous neural networks," Journal of Computing in Civil Engineering, vol. 27, no. 6, pp. 755-768, 2013. 